\title{
위염전
}

\author{
차라리, 김현진 \\ 경상대학교 의과대학 창원경상대학교병원 내과
}

\section{Gastric Volvulus}

Ra Ri Cha and Hyun Jin Kim

Department of Internal Medicine, Gyeongsang National University Changwon Hospital, Gyeongsang National University College of Medicine, Changwon, Korea

증례: 82세 여자가 약 1 개월 전부터 시작된 전신 쇠약감 및 식사량 감소로 창원경상대학교병원에 전원되었다. 환자는 수년 전부터 파킨슨병과 알츠하이머병으로 약물 치료 중이었다. 가족력은 없었고 음주력 및 흡연력은 부인하였다. 내원 당시 혈압 92/64 mmHg, 맥박수 84회/분, 호흡수 18회/분, 체온 $37^{\circ} \mathrm{C}$ 로 측정되었다. 복부 진찰에서 복부 팽만이 보였고, 상복부 압통은 있었으나 반발통은 없었다. 복부 청진에서 특이 소견은 없었다. 말초혈액 검사에서 백혈구 $7,710 / \mathrm{mm}^{3}$ (중성구 $73.9 \%$, 임파구 $17.0 \%$, 단핵구 $6.4 \%$, 호산구 $2.0 \%$, 호염구 $0.7 \%$, 혈색소 $11.0 \mathrm{~g} / \mathrm{dL}$, 혈소판 202,000/ $\mu \mathrm{L}$ 였고, 전해질 검사에서 나트륨 $136 \mathrm{mmol} / \mathrm{L}$, 칼륨 $4.2 \mathrm{mmol} / \mathrm{L}$, 염소 $103.1 \mathrm{mmol} / \mathrm{L}$ 였다. 혈청 생화학 검사에서 총 빌리루빈 $0.76 \mathrm{mg} / \mathrm{dL}, \mathrm{AST} 39 \mathrm{U} / \mathrm{L}, \mathrm{ALT}$ $20 \mathrm{U} / \mathrm{L}$, 크레아티닌 $0.54 \mathrm{mg} / \mathrm{dL}, \mathrm{ALP} 72 \mathrm{U} / \mathrm{L}$, 알부민 $3.7 \mathrm{~g} / \mathrm{dL}$, $\mathrm{C}$-반응성 단백 $0.84 \mathrm{mg} / \mathrm{dL}$ 였다.

복부 전산화단층촬영에서 위의 심한 팽만과 해부학적 변위 소견을 보였다. 유문부와 십이지장이 전상방으로 전위되고, 기저부와 분문부는 후하방으로 전위되어 위염전이 의심되었 다(Fig. 1). 상부위장관 내시경 검사에서 위저부에 소화되지 않은 음식물이 남아 있었으며, 식도 주위 탈장이 동반되어 있 지는 않았다. 위체부 상부에서부터 심한 굴곡으로 인하여 원 위부로의 연결부가 급격히 좁아져 있었고, 관찰 가능한 범위 의 위저부의 위점막에서 일부의 허혈성 궤사 및 백태 등이
관찰되었고, 내시경 선단이 유문륜으로 접근되지 않고 위폐쇄 소견을 보였다(Fig. 2). 다시 몇 차례 내시경으로 전정부 진입 을 시도하여 내시경이 비틀어진 상태에서 십이지장으로 진입 하고 내시경을 회전하면서 뒤로 당기는 방법으로 위정복술을 시행하였다. 성공적으로 위정복 후 내시경 관찰에서 정상적으 로 위전정부로 진입이 가능하고, 위체부 및 위전정부를 관찰 할 수 있었다(Fig. 3). 이후 임상적으로 복부 불편감과 복부 팽만이 소실되었고 식이를 진행하면서 통증 호소가 없어 퇴원 후 외래에서 추적 관찰하였다. 현재까지 재발 등의 특이 소견 은 없다.

\section{진단: 위염전}

위염전은 위의 일부가 비정상적으로 회전하여 180도 또는 그 이상 혹은 폐색이 일어날 정도로 돌아가는 드문 질환이다. ${ }^{1}$ 발생 비율은 남녀에서 차이가 없고, 성인에서는 주로 50대에 서 많이 발생하며, 전체 위염전의 약 15-25\%는 1세 미만에서 발생한다. ${ }^{2}$

위염전은 1866년 Berti가 사체에서 처음 발견하였고, 1895년 Berg가 처음으로 외과적 치료를 하였다. ${ }^{1}$ 위는 정 상적으로 주변의 여러 인대를 비롯한 구조물들에 고정되어 형태를 유지하는 데 복강 내의 특별한 이상이 없이 원발성 으로 발생하는 경우도 있으나 대부분의 경우 해부학적으로

(C) This is an open access article distributed under the terms of the Creative Commons Attribution Non-Commercial License (http://creativecommons.org/licenses/ by-nc/4.0) which permits unrestricted non-commercial use, distribution, and reproduction in any medium, provided the original work is properly cited. Copyright (C) 2020. Korean Society of Gastroenterology.

교신저자: 김현진, 51472 , 창원시 성산구 삼정자로 11 , 창원경상대학교병원 내과

Correspondence to: Hyun Jin Kim, Department of Internal Medicine, Gyeongsang National University Changwon Hospital, 11 Samjeongja-ro, Seongsan-gu, Changwon 51472, Korea. Tel: +82-55-214-3710, Fax: +82-55-214-3250, E-mail: imdrkim@naver.com, ORCID: https://orcid.org/0000-0003-3853-0229

Financial support: None. Conflict of interest: None. 
주위 인대 중 하나 이상이 선천적으로 없거나 비정상적인 끈이나 유착, 식도 주위 탈장(paraesophageal hernia)이 있 을 때 위하수(gastroparesis)에 의한 주위 인대의 이완, 십 이지장의 이상부착, 외상 및 수술, 좌측 횡격막의 상승이 있
을 때 등으로 발생한다.,4

위염전의 분류는 종축형(organoaxial)과 횡축형(mesenteroaxial) 그리고 혼합형(combination type)으로 나누어진다. ${ }^{5}$ 위염전 의 약 $2 / 3$ 에서 종축형이며, 이는 분문부와 십이지장의 제 2 부위
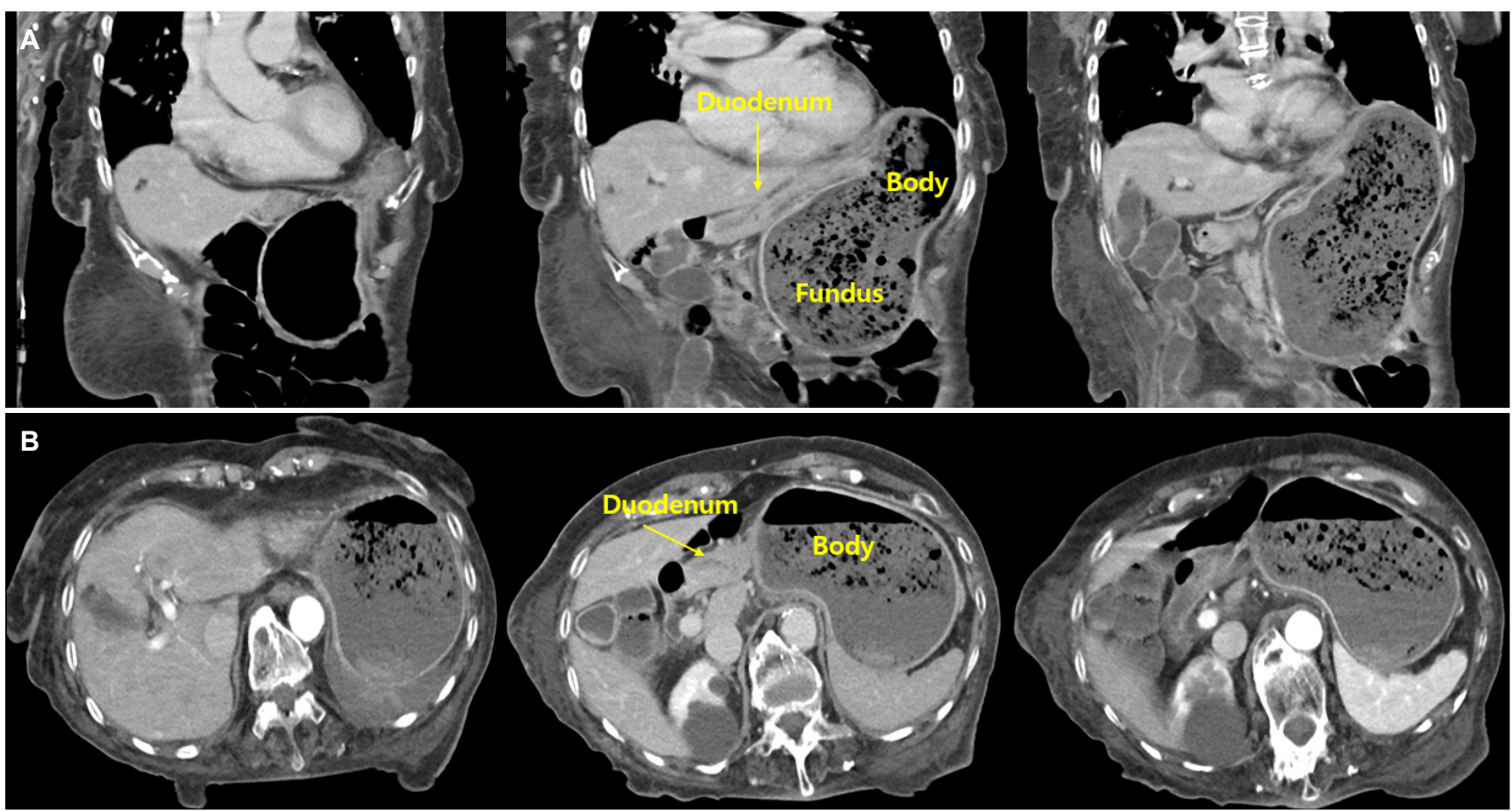

C
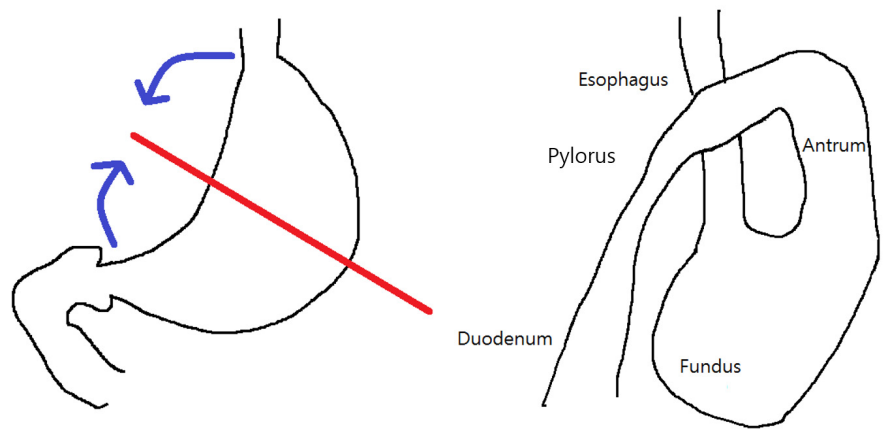

Fig. 1. Abdominal computed tomography (CT) shows marked gastric distension and its anatomical alteration. (A) Coronal CT images. (B) Axial CT images. (C) Schematic representation of mesentero-axial volvulus.
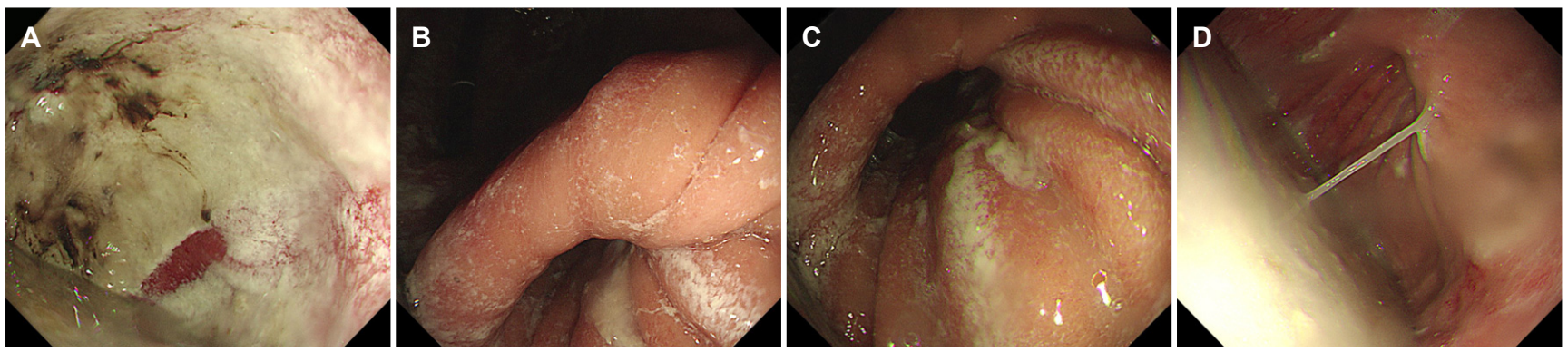

Fig. 2. The gastroscopy shows distended funds and anterior rotation of the body portion and abrupt narrowing of the antrum, resulting in gastric outlet obstruction. (A) Gastric fundus. (B) Gastric angle. (C) Gastric antrum. (D) Gastric body. 


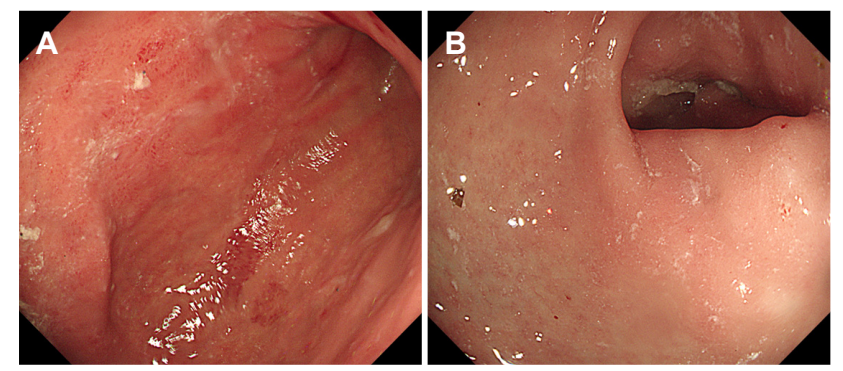

Fig. 3. The post-procedural gastroscopy shows normal lumen of the body and antrum which was previously shown as twisted. (A) Gastric body. (B) Gastric antrum.

를 두 고정축으로 하여 앞쪽으로 혹은 뒤쪽으로 회전한다. 또한 약 $1 / 3$ 에서 횡축형이며 이는 종축형의 회전축에 수직인 대만부 와 소만부를 있는 선을 따라 회전한다. 염전의 범위에 따라 위 전체가 회전하는 전체형(total type)과 위의 일부가 회전하 는 부분형(partial type)으로 분류하거나, 회전하는 방향에 따 라 시계 방향으로 염전되는 전방형(anterior type)과 반시계 방향으로 염전되는 후방형(posterior)이 있다. 선행 질환의 유무 에 따라 특발성(idiopathic) 또는 이차성(secondary)으로 나뉜 다. ${ }^{5,6}$

위염전의 증상은 발생 시기와 염전의 분류 및 정도에 따라 차이가 있다. 급성 위염전의 3대 증상으로 첫째, 상복부의 심 한 동통 및 팽만, 둘째, 심한 오심과 양이 적은 구토, 셋째, 위관 삽입의 곤란 등이 있다. 이를 Borchardt's triad라 하고 전체 약 $70 \%$ 의 환자에서 나타난다. 위염전의 정도에 따라 불 완전 염전으로 인한 증상은 상복부 동통, 팽만감, 소화불량 등의 증상이 나타나며, 완전 염전의 경우는 갑작스러운 상복 부 동통 및 팽만감, 지속되는 오심, 위관 삽입 곤란이 나타나 며, 일부 환자에서 혈액순환 장애로 인한 괴저가 발생하여 위 장관 출혈, 급성 신부전, 쇼크 등이 발생할 수 있다. ${ }^{7.8}$ 만성 위염전은 주로 무증상이거나 수개월에서 수년에 걸쳐 간헐적 인 상복부 불쾌감 혹은 복통, 조기 복부 팽만, 식후 불편감 등이 있다. ${ }^{9}$ 감별해야 할 질환으로는 급성 위염전의 경우 소화 성 궤양 천공, 급성 췌장염, mesenteric vascular accident, 급성 담낭염, 난소낭종의 염전 등과 감별해야 하며, 만성 위염 전의 경우 소화성 궤양, 식도탈장, 위염, 만성 췌장염, 담도계 질환과 감별해야 한다. ${ }^{4}$

진단은 방사선학적으로 진단이 가능하며 단순 흥부촬영에 서 횡격막 상부에 공기층을 포함한 음영이 관찰되면 의심할 수 있고, 상부위장관 조영술에서 조영제가 위장을 통과하지 못하고 비정상적으로 위가 회전되어 있다면 확진이 가능하다. 복부 전산화단층촬영을 통해 확진이 가능하며, 염전의 분류 및 방향, 탈장의 동반 여부 등이 확인 가능하다. 상부위장관 내시경 검사는 내시경 진입 시 위점막 주름이 꼬여 있고 회전
하여 전정부로 내시경 진입이 어렵거나, 심하게 굴절되어 위 중격 형성(septal formation)이 관찰되면 진단이 될 수 있 다. ${ }^{10}$

급성 위염전의 대부분은 위염전으로 인한 허혈성 괴사, 천 공, 쇼크, 사망을 막기 위해 즉각적인 수술 치료가 필요하다. 수술의 목적은 염전을 풀고 재발을 방지하는 것으로 수술 전 에 먼저 비위관을 삽입하여 감압시키는 것이 필요하다. ${ }^{11}$ 위염 전을 상부위장관 내시경으로 정복하는 경우도 있으며, 대부분 만성의 예이다. 상부위장관 내시경을 이용한 치료 방법은 alpha-loop를 통한 정복술을 시도할 수 있다. 먼저 내시경을 좁 아진 위 내로 조심스럽게 진행시켜 통과 여부를 확인하고, 다 시 근위부에서 내시경 선단을 후굴(retroflexion)한 상태로 alpha-loop를 형성하며 전정부를 통과시킨다. 이후 시계방향으 로 내시경을 돌리면서 alpha-loop를 풀어 위염전을 정복하는 방법이다. 내시경을 통한 정복술을 허혈로 인한 천공의 가능 성이 있을 때는 시도하지 않아야 한다. 만성 위염전의 경우 위관의 삽입, 수액 공급 등 대증요법으로 치료가 될 수 있으나 재발율은 높은 편이다. ${ }^{12}$ 위염전의 합병증으로는 비장혈관의 파열, 궤양, 천공, 출혈, 췌장궤사 및 대망 분리 등이 있다. 급성 위염전의 사망률은 $15-20 \%$ 이며, 만성 위염전은 0-13\% 까지 보고되고 있다. ${ }^{13}$

본 증례는 고령의 식사량 감소 및 복통을 주소로 내원한 환자에서 복부 전산화단층촬영을 통해 위염전을 진단하였고, 위내시경 검사를 통해 진단 및 정복술을 통한 치료를 시행한 증례이다. 위염전은 180도 이상 혹은 폐쇄가 일어날 정도로 위가 회전이 되는 질환으로 매우 드물지만 급성 발병 시 허혈 및 괴사가 합병될 수 있어 빠른 진단과 적절한 치료가 필요하 다. ${ }^{14,15}$

\section{REFERENCES}

1. Tanner NC. Chronic and recurrent volvulus of the stomach with late results of "colonic displacement". Am J Surg 1968;115: 505-515.

2. Wastell $\mathrm{C}$, Ellis $\mathrm{H}$. Volvulus of the stomach. A review with a report of 8 cases. Br J Surg 1971;58:557-562.

3. Ascherman SW, Bednarz WW, Olix ML. Gastric volvulus; special reference to hepatodiaphragmatic interposition of colon. AMA Arch Surg 1958;76:621-629.

4. Smith RJ. Volvulus of the stomach. J Natl Med Assoc 1983; 75:393-397.

5. Kim HH, Park SJ, Park MI, Moon W. Acute intrathoracic gastric volvulus due to diaphragmatic hernia: a rare emergency easily overlooked. Case Rep Gastroenterol 2011;5:272-277.

6. McElreath DP, Olden KW, Aduli F. Hiccups: a subtle sign in the clinical diagnosis of gastric volvulus and a review of the literature. Dig Dis Sci 2008;53:3033-3036.

7. Wasselle JA, Norman J. Acute gastric volvulus: pathogenesis, 
diagnosis, and treatment. Am J Gastroenterol 1993;88: 1780-1784.

8. Schaefer DC, Nikoomenesh P, Moore C. Gastric volvulus: an old disease process with some new twists. Gastroenterologist 1997; 5:41-45.

9. Haas O, Rat P, Christophe M, Friedman S, Favre JP. Surgical results of intrathoracic gastric volvulus complicating hiatal hernia. Br J Surg 1990;77:1379-1381.

10. Peterson CM, Anderson JS, Hara AK, Carenza JW, Menias CO. Volvulus of the gastrointestinal tract: appearances at multimodality imaging. Radiographics 2009;29:1281-1293.

11. Teague WJ, Ackroyd R, Watson DI, Devitt PG. Changing patterns in the management of gastric volvulus over 14 years. $\mathrm{Br} J$ Surg 2000;87:358-361.

12. Tsang TK, Walker R, Yu DJ. Endoscopic reduction of gastric volvulus: the alpha-loop maneuver. Gastrointest Endosc 1995; 42:244-248.

13. Pillay SP, Angorn IB, Baker LW. Gastric volvulus unassociated with hiatal hernia. S Afr Med J 1977;52:880-885.

14. Morimachi M, Nakahara F, Kaneko M, et al. A case of mesentero-axial type of acute gastric volvulus successfully reduced by a balloon-assisted endoscopy. Tokai J Exp Clin Med 2019;44:5-8.

15. Pak K, Junga Z, Young P. An acute presentation of chronic gastric volvulus. ACG Case Rep J 2020;7:e00297. 